\title{
Gingival hyperplasia as first sign of recurrence of granulomatosis with polyangiitis (Wegener's granulomatosis): case report and review of the literature
}

\author{
Marcel Hanisch*, Leopold F. Fröhlich and Johannes Kleinheinz
}

\begin{abstract}
Background: Granulomatosis with polyangiitis (GPA), formerly referred to as Wegener's granulomatosis, is a rare systemic disease of unknown etiology which can affect all areas of the body, including the oral cavity. The typical oral manifestations occur as nonspecific erosive/ulcerative lesions of the oral cavity or appear with hyperplastic gingivitis, a so called "strawberry gingivitis".

Case presentation: We report here about an extremely rare case with hyperplastic gingivitis as the first sign of recurrence of GPA in the absence of oral manifestations in the primary disease. A 72 year-old female was referred to our Department of Cranio-Maxillofacial Surgery with hyperplastic gingivitis. The patient was diagnosed with GPA already eight years before. We referred the patient to our Clinic of Internal Medicine where she was successfully treated with rituximab. At the follow-up visit, the patient showed complete remission of the hyperplastic gingiva.

Conclusion: The often overlooked oral manifestation may be interpreted as the first evidence of resurgent GPA in general and therefore could be pathognostic for the disease. This case affirms the need of health professionals to be acquainted with orofacial manifestations of rare diseases such as GPA. As a consequence, dentists will be able to assist in diagnosing GPA more easily leading to a better prognosis for patients suffering from this disease.
\end{abstract}

Keywords: Granulomatosis with polyangitis, Orofacial manifestation, Recurrence, Rituximab, Strawberry gingivitis, Wegener's granulomatosis

\section{Background}

GPA, formerly referred to as Wegener's granulomatosis, is a rare, systemic disease of unknown etiology characterized by necrotizing granulomatous inflammation of the upper and lower respiratory tract, glomerulonephritis and vasculitis [1]. Moreover, nasal deformations with saddle nose manifestation, sinusitis and ulceration of the palate or nasal mucosa are not extraordinary in GPA. General GPA can affect all areas of the body, including the oral cavity [2, 3]. In European Union countries, any disease affecting less than one person in 2.000 is considered "rare" [4]. GPA has a prevalence of 1-9/ 100.000 and therefore is listed as a rare disease [5].

\footnotetext{
* Correspondence: marcel.hanisch@ukmuenster.de

Department of Cranio-Maxillofacial Surgery, University Hospital Münster, Albert-Schweitzer-Campus 1, Gebäude W 30, D-48149 Münster, Germany
}

About 5.000 rare diseases are of genetic origin and approximately $15 \%$ of these present manifestations at the orofacial region [6]. Oral symptoms in GPA have been reported in 10-62 \% [7]. The typical oral manifestations occur as nonspecific erosive/ulcerative lesions of oral cavity or appear with hyperplastic gingivitis, a so-called "strawberry gingivitis". GPA can affect patients at any age, whereas diagnosis is mostly done when patients range between 40 and 55 years of age. The disease is more common in Caucasians and no gender-specific differences were identified [8]. The pathogenetic cause of GPA is mediated by a T-cell reaction leading to the production and release of pro-inflammatory cytokines like TNF- $\alpha$ and IFN- $\gamma$ which induce the expression of surface antigens on activated neutrophil granulocytes. One of these antigens is proteinase 3 which is the target 
of antineutrophil cytoplasmatic antibodies (c-ANCA). This interaction leads to degranulation of neutrophil granulocytes which release proteases and effector molecules being responsible for the tissue damage [9]. Generally, the clinical manifestation of the disease varies from patient to patient. Rapid progression in combination with multiorgan failure will lead to death if untreated [10]. Two types of GPA are known: diffuse forms, manifesting primarily by renal and pulmonary contribution and localized forms, limited to the upper respiratory tract. Localized forms are in contrast to diffuse forms more recurrent while diffuse forms are initially more fatal but less recurrent $[11,12]$. A transition from limited to localized GPA and the other way around is possible [12]. Since the disease develops over an extended period of time, it usually takes 4.7-15 months from the beginning of the symptoms to the diagnosis [8]. The American College of Rheumatology proposes that for the diagnosis of "GPA" two or more of the following criteria have to be fulfilled: (1) ulcerative lesions in the oral mucosa or nasal bleeding or swelling, (2) nodules, infiltrates or cavities on chest radiograph, (3) abnormal urinary sediment, or (4) granulomatous inflammation on biopsy [13]. Here, we report about an extremely rare case with gingival hyperplasia as the first sign of recurrence of GPA in the absence of oral manifestations in the primary disease.

\section{Case presentation}

A 72 year-old female was transferred to our Department of Cranio-Maxillofacial Surgery at the University Hospital of Münster with a hyperplastic gingivitis and intraoral pain in October 2015.

\section{Patient history}

The patient was diagnosed with GPA already in 2007. Since that time she has developed glomerulonephritis, nephrosclerosis, pulmonary emphysema, Raynaud's phenomenon, sinusitis maxilliaris and had surgery on an orbital pseudotumor in 2014. Since the first diagnosis of GPA in 2007 the patient was treated with prednisolone and cyclosporine. She also suffered from a steroid-associated osteoporosis which has been treated intravenously with denosumab, a human monoclonal antibody directed towards osteoclastmediated bone resorption by binding to osteoblastproduced RANKL. Mild hypertonia and presbyacusia of both ears were also diagnosed. Oral manifestations like "strawberry gingivitis" did not occur since the first diagnosis of GPA in 2007, but a basal cell carcinoma developed in 2015. The patient was first diagnosed with hyperplastic gingivitis by her dentist in April 2015 and was treated subsequently by non-surgical periodontal therapy without antibiotics. However, since

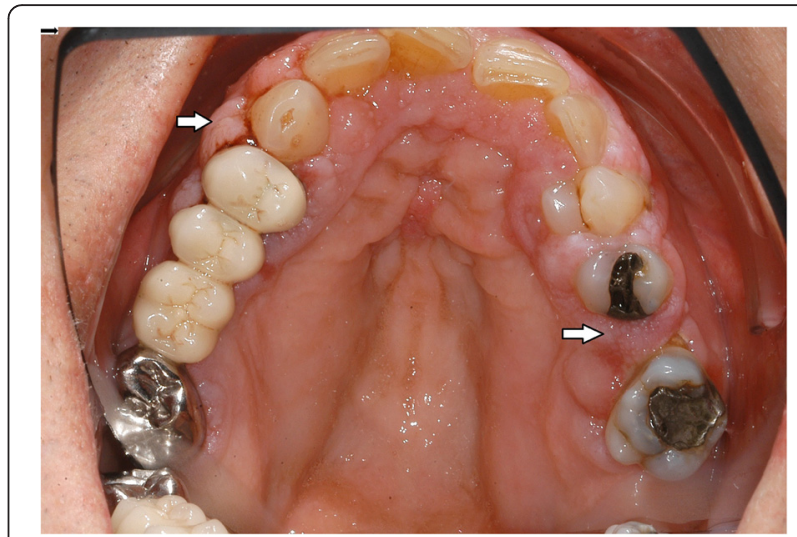

Fig. 1 Photographical Image of oral lesion at initial presentation

the therapy lacked any beneficial effect the patient was sent to a periodontist in September 2015. The periodontist did not conduct any treatment. He recommended gingivectomy of the hyperplastic gingiva and due to the additional intravenous denosumab therapy, he transferred the patient to our Department for further treatment.

\section{Oral examination}

In the intraoral examination, alterations of the gingival volume were observed. Plaque control was poor since handling with the toothbrush was too difficult for the patient. Additionally, we noted the absence of petechia on the buccal and oral gingiva in the upper as well as in the lower jaw and bleeding in the buccal area of 13-15. (Figs. 1 and 2). She described intraoral pain and was handicapped during food intake. In the orthopantomogram the patient showed an impacted canine, furcation involvement of the first upper molars, and horizontal bone loss according to the age (Fig. 3). Thus, the gingival volume appeared uncommon.

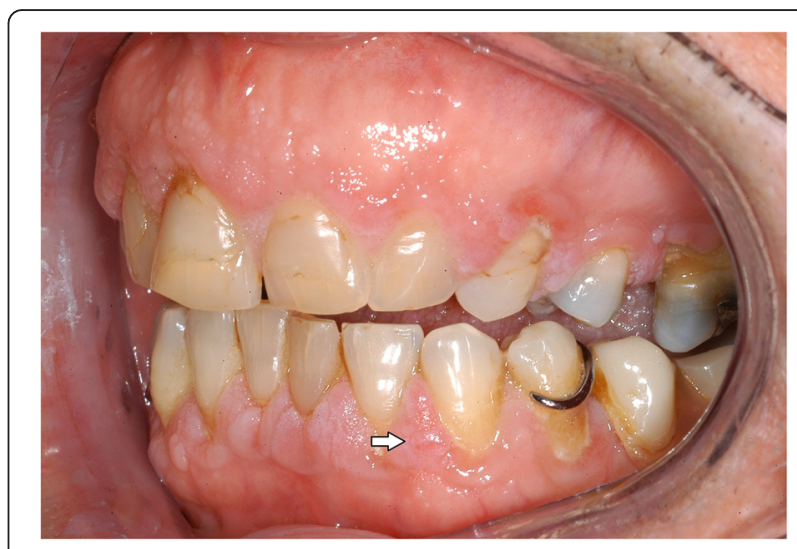

Fig. 2 Photographical image of the oral lesion at initial presentation 


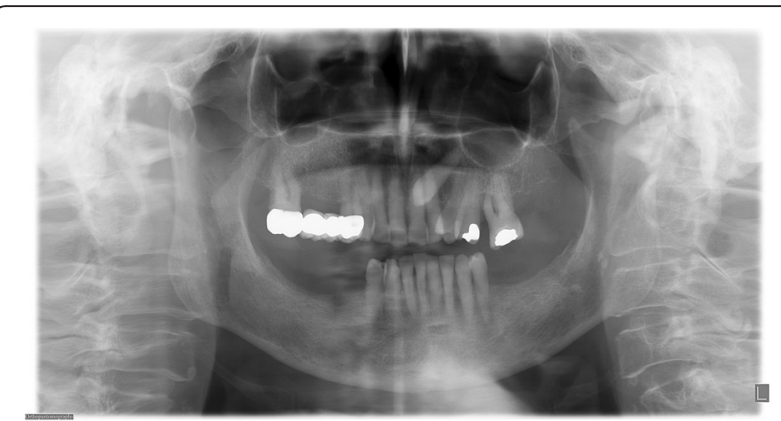

Fig. 3 Panoramic radiograph with impacted canine, furcation involvment of the upper molars and horizontal bone loss according to the age

\section{Present medication}

At the time of the patient's visit at our Department the medication for the therapy of GPA consisted of a combination of prednisolone $10 \mathrm{mg} /$ day and cyclopsporine $150 \mathrm{mg} /$ day prescribed by her family doctor. The patient's full medication is presented in Table 1.

\section{Therapy}

As periodontal therapy has previously failed and cyclosporine has been given since 2007 without any intraoral side-effects like gingival hyperplasia, we decided in suspicion of the recurrence of GPA with gingival hyperplasia to take a biopsy from the palatinal premolar region under local anesthesia. The biopsy was then sent for routine histopathological analysis which revealed inflammation with parakeratosis and neutrophil-granulocytic infiltration (Fig. 4). These findings were conveyed to her family doctor who decided to refer the patient to the Clinic of Internal Medicine at the University Hospital of Münster. Since the staining for c-ANCA tested positive, the recurrence of GPA was suspected. Therefore, they decided to treat the patient with rituximab via infusion. In addition to prednisolone $10 \mathrm{mg} /$ day, the patient was given $375 \mathrm{mg} / \mathrm{m}^{2}$ rituximab weekly for a total of 4 doses. After one week of therapy, she was re-evaluated at our

Table 1 Patient's full medication

\begin{tabular}{ll}
\hline Medication & Dosage per day \\
\hline Amlodipine & $10 \mathrm{mg}$ \\
Flecainide acetat & $50 \mathrm{mg}$ \\
Xipamide & $5 \mathrm{mg}$ \\
Prednisolone & $10 \mathrm{mg}$ \\
Ciclosporine & $150 \mathrm{mg}$ \\
Omeprazole & $40 \mathrm{mg}$ \\
L-Thyroxine & $125 \mu \mathrm{g}$ \\
Metamizole & $500 \mathrm{mg}$ \\
Vitamin D3 & $1200 \mathrm{mg}$ \\
\hline
\end{tabular}

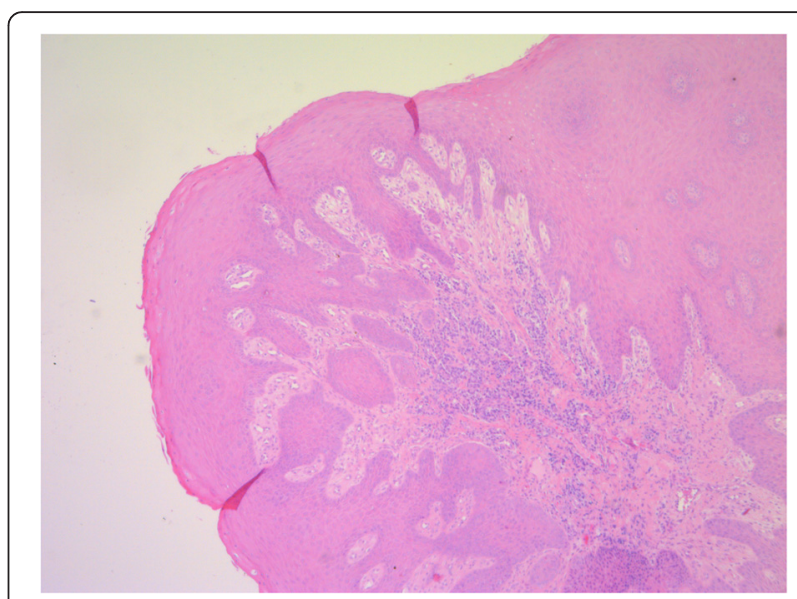

Fig. 4 Histology of chronic, florid inflammation with stratified epithelium, parakeratosis, increased capillarization and intraepithelial neutrophilic granulocyte infiltration stained with hematoxylin and eosin (PAS, magnification: 100-fold)

Department. At the follow-up visit, the patient showed complete remission of the hyperplastic gingiva (Figs. 5 and 6), the absence of pain, and the patient was able to eat without problems. Periodontal probing depths of $5 \mathrm{~mm}$ or more only appeared at the molars. Table 2 shows the diagnostic and treatment process of the patient in chronological order.

\section{Discussion}

Cases of GPA with oral symptoms were described in several reports $[2,3,7,14-18]$. However, a systematic search in PubMed generated by "granulomatosis with polyangiitis, Wegener's granulomatosis, gingivitis, recurrent, recurrence" indicated only one report describing the recurrence of GPA without any oral symptoms in the initial presentation of the disease reported by Staines et al. [14]. Comparable to our case, gingival hyperplasia was evident only on recurrence in this single reported

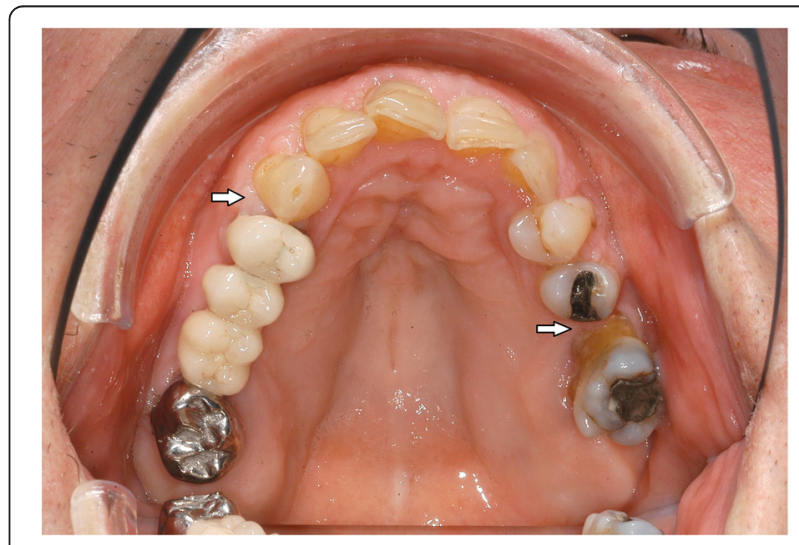

Fig. 5 Resolution of the oral lesion in Fig. 1 following therapy with rituximab 


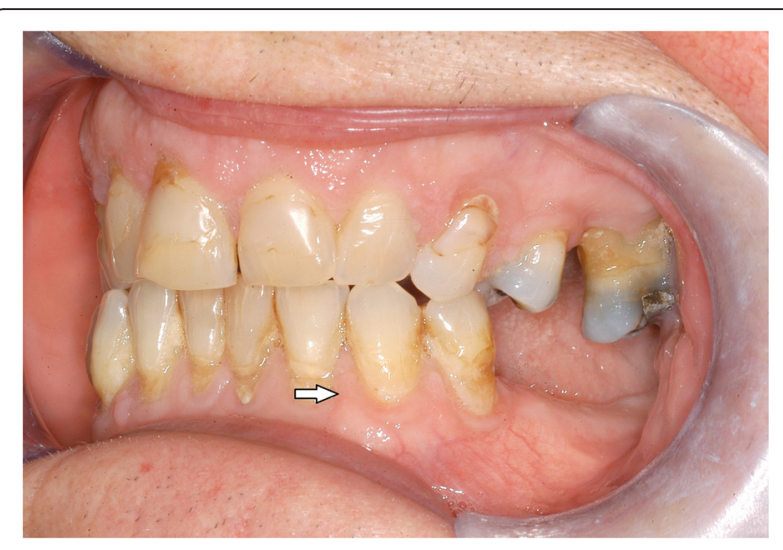

Fig. 6 Resolution of the oral lesion in Fig. 2 following therapy with rituximab

case. The standard therapy of initial GPA consisted of glucocorticoids or cyclophosphamide, or a combination of both [19]. Although standard therapy does improve the survival rate of the patients, there are also therapyrelated malignancies like squamous cell carcinoma, Kaposi sarcoma or basal cell carcinoma which was also applicable to our patient [20]. In contrast to the standard therapy of initial GPA, there are reports of successful treatment of refractory head and neck GPA with rituximab [14]. Rituximab is a chimeric, monoclonal antibody targeting the CD20-antigen expressed by B-cells. Successful treatment with rituximab leading to full remission is reported in $62 \%$ of all treated patients by Martinez et al. [21]. About $15 \%$ of all rare diseases show orofacial manifestations [6, 22]. Typical oral manifestations in GPA are unspecific erosive lesions in the oral mucosa or hyperplastic gingivitis as reported here. Differential diagnosis for the gingival enlargement could be caused by medications [2] (such as phenytoin, cyclosporine and some oral contraceptives), other granulomatous diseases like sarcoidosis and Crohn's disease or blood dyscrasia like leukemia [7]. Since oral lesions can be localized a long time before multiorgan involvement actually occurs [15], the often overlooked oral manifestation may be interpreted as the first sign of GPA and could be pathognostic for the disease. Histopathological pattern of GPA include granulomatous inflammation, vasculitis, necrosis and multinucleated giant cells. Often, however, histopathological findings are less specific and cannot be considered as clinical diagnostics [16]. Furthermore, it is known that rare diseases with oral components benefit more from an early diagnosis than rare diseases without oral components [23]. Misdiagnosed oral manifestations which are often overlooked by physicans and by dentists may be interpreted as the first evidence of resurgent GPA in general and therefore could be pathognostic for the disease. A dental specialist has a high chance of identifying GPA based on the characteristics of the oral findings. Moreover, the dentist might be the first one being consulted by the patient with oral manifestations such as gingival hyperplasia. Gingival hyperplasia that is not associated with remission after periodontal therapy or with drug delivery should be investigated then with regard to internal diseases like GPA or leukemia. This example affirms why health professionals should be acquainted with orofacial manifestations of rare diseases such as GPA. As a consequence faster referrals to other medical specialists like rheumatologist, nephrologist, or pulmonologist will be possible and enable them to start with the treatment early on, on the one hand [17]. On the other hand, dentists may receive referrals from physicans for evaluating oral symptoms.

\section{Conclusions}

Overall, this case demonstrates an important role for the dentist in the early diagnosis of GPA. Instead of gingivectomy with conceivably fatal consequences, treatment of the underlying disease based on oral symptoms was performed. In conclusion, dentists should be acquainted with orofacial manifestations of rare diseases such as GPA, because they could be the first in detecting early symptoms of a rare disease. Thus, the dentist will be able to assist in the early diagnosis of this fatal rare disease more easily which is the most important factor in the management and prognosis for patients suffering from GPA or other rare diseases [18].

Table 2 The patient's diagnostic and treatment process in chronological order

\begin{tabular}{|c|c|c|c|c|}
\hline 2007 & $2007-2015$ & April-October 2015 & $\begin{array}{l}\text { October 2015- } \\
\text { February } 2016\end{array}$ & December 2015-January 2016 \\
\hline $\begin{array}{l}\text { First diagnosis of } \\
\text { GPA diagnosed by } \\
\text { glomerulon ephritis }\end{array}$ & $\begin{array}{l}\text { Permanent medication with } \\
\text { prednisolone and cyclosporine. } \\
\text { Development of a steroid- } \\
\text { associated osteoporosis treated } \\
\text { intravenously with denosumad. } \\
\text { Over the time developing } \\
\text { pulmonary emphysema, } \\
\text { Raynaud's phenomenon, } \\
\text { sinusitis maxilliaris and orbital } \\
\text { pseudotumor. }\end{array}$ & $\begin{array}{l}\text { Development of gingival hyperlpasia. } \\
\text { In the following periodontal theraphy } \\
\text { without benefit by her dentist. Thus } \\
\text { reffered to periodontist. } \\
\text { Recommendation for gingivectomy, } \\
\text { transfer to Department of } \\
\text { Cranio-Maxillofacial Surgery, } \\
\text { University Hospital Münster. } \\
\text { Biospsy from hyperplastic } \\
\text { gingivitis taken }\end{array}$ & $\begin{array}{l}\text { Ambulant follow-up } \\
\text { in the Department } \\
\text { of Cranio-Maxillofacial } \\
\text { Surgery, University } \\
\text { Hospital Münster. }\end{array}$ & $\begin{array}{l}\text { Suspiction of recurrence of GPA } \\
\text { by increasing (c)-ANCA and } \\
\text { clinical signs of recurrence. } \\
\text { Stationary therapie at Internal } \\
\text { Medicine Clinic, University } \\
\text { Hospital Münster. In the } \\
\text { following } 375 \mathrm{mg} / \mathrm{m}^{2} \text { rituximab } \\
\text { weekly for a total of } 4 \text { doses, } \\
\text { and prednisolone } 10 \mathrm{mg} / \text { day. }\end{array}$ \\
\hline
\end{tabular}




\section{Abbreviations}

c-ANCA, antineutrophil cytoplasmatic antibodies; GPA, granulomatosis with polyangiitis

\section{Acknowledgements}

The authors thank the patient who allowed the publication of this case report. We acknowledge support by Open Access Publication Fund of University of Muenster.

\section{Funding}

This research did not receive any specific grant from funding agencies in the public, commercial, or not-for-profit sectors.

\section{Availability of data and materials}

The datasets supporting the conclusions of this article are available at the Department of Cranio-Maxillofacial Surgery, University Hospital Münster Germany.

\section{Authors' contributions}

MH conceived the case. LFF and JK helped in the acquisition and interpretation of data. MH, LFF, and JK participated in literature review, design, and drafting of the manuscript. All authors read and approved the final manuscript.

\section{Competing interests}

The authors declare that they have no competing interests.

\section{Consent for publication}

Written informed consent was obtained from the patient for publication of this case report and any accompanying images. A copy of the written consent is available for review by the Editor-in-Chief of this journal.

\section{Ethics approval and consent to participate}

Not applicable.

Received: 1 March 2016 Accepted: 29 July 2016

Published online: 02 August 2016

\section{References}

1. Boomsma MM, Stegemann CA, Van Der Leij MJ, Osst W, Hermans J, Kallenberg CGM, Limburg PC, Tervaert JW. Prediction of relapses in Wegener's granulomatosis by measurement of antineutrophil cytoplasmic antibody levels: a prospective study. Arthritis Rheum. 2000:43(9):2025-33.

2. Ruokonen H, Helve T, Arola J, Hietanen J, Lindqvist C, Hagstrom J. "Strawberry like" gingivitis being the first sign of Wegener's granulomatosis. Eur J Intern Med. 2009;20(6):651-3.

3. Reboll-Ferrer RM, Zapater-Latorre E, Calabuig-Crespo C, Basterra-Alegría J. Wegener's granulomatosis: description of a case with oral manifestation. Med Oral Patol Oral Cir Bucal. 2010;1:15(4).

4. Regulation (EC) No 141/2000 of the European Parliament and of the Council of 16 December 1999 on orphan medical products (OJ L 18, 22.1. 2000, p. 1). http://ec.europa.eu/health/files/eudralex/vol-1/reg_2000_141_ cons-2009-07/reg_2000_141_cons-2009-07_en.pdf Accessed 23 Jan 2016.

5. http://www.orpha.net: Granulomatosis with polyangiitis. http://www.orpha. net/consor/cgi-bin/OC_Exp.php?Expert=900\&lng=EN Accessed 22 Jan 2016.

6. John Hopkins University. OMIM - Online Catalog of Human Genes and Genetic Disorders. [www.ncbi.nlm.nih.gov/omim] Accessed 22 Jan 2016.

7. Stewart C, Cohen D, Bhattacharyya I, Scheitler L, Riley S, Calamia K, Migliorati C, Baughman R, Langford P, Katz J. Oral manifestations of Wegener's granulomatosis: a report of three cases and a literature review. J Am Dent Assoc. 2007;138(3):338-48.

8. Hoffman GS, Kerr GS, Leavitt RY, Hallahan CW, Lebovics RS, Travis WD, Rottem M, Fauci AS. Wegener granulomatosis: an analysis of 158 patients. Ann Intern Med. 1992;116(6):488-98.

9. Lutalo PM, D'Cruz DP. Diagnosis and classification of granulomatosis with polyangiitis (aka Wegener's granulomatosis). J Autoimmun. 2014;48-49:94-8.

10. Hinze CH, Colbert RA. B-cell depletion in Wegener's granulomatosis. Clin Rev Allergy Immunol. 2008;34(3):372-9.

11. Holle JU, Gross WL, Holl-Ulrich K, Ambrosch P, Noelle B, Both M, Csernok E, Moosig F, Schinke S, Reinhold-Keller E. Prospective long-term follow-up of patients with localised Wegener's granulomatosis: does it occur as persistent disease stage? Ann Rheum Dis. 2010;69(11):1934-9.

12. Comarmond C, Cacoub P. Granulomatosis with polyangiitis (Wegener): clinical aspects and treatment. Autoimmun Rev. 2014;13(11):1121-5.

13. Leavitt RY, Fauci AS, Bloch DA, Michel BA, Hunder GG, Arend WP, Calabrese LH, Fries JF, Lie JT, Lightfoot Jr RW, Masi AT, McShane DJ, Mills JA, Stevens MB, Wallace SL, Zvaifler NJ. The American College of Rheumatology 1990 criteria for the classification of Wegener's granulomatosis. Arthritis Rheum. 1990;33(8):1101-7.

14. Staines KS, Higgins B. Recurrence of Wegener's granulomatosis with de novo intraoral presentation treated successfully with rituximab. Oral Surg Oral Med Oral Pathol Oral Radiol Endod. 2009;108(1):76-80.

15. Handlers JP, Waterman J, Abrams AM, Melrose RJ. Oral features of Wegener's granulomatosis. Arch Otolaryngol. 1985;111(4):267-70.

16. Aravena V, Beltrán V, Cantín M, Fuentes R. Gingival hyperplasia being the first sign of Wegener's granulomatosis. Int J Clin Exp Med. 2014;7(8):2373-6.

17. Ponniah I, Shaheen A, Shankar KA, Kumaran MG. Wegener's granulomatosis: the current understanding. Oral Surg Oral Med Oral Pathol Oral Radiol Endod. 2005;100(3):265-70.

18. Knight JM, Hayduk MJ, Summerlin DJ, Mirowski GW. "Strawberry" gingival hyperplasia: a pathognomonic mucocutaneous finding in Wegener granulomatosis. Arch Dermatol. 2000;136(2):171-3.

19. Hoffman GS. Wegener's granulomatosis. Curr Opin Rheumatol. 1993;5:11-7.

20. Aasarod K, Iversen BM, Hammerstrom J, Bostad L, Vatten L, Jorstad S. Wegener's granulomatosis: clinical course in 108 patients with renal involvement. Nephrol Dial Transplant. 2000;15(12):2069.

21. Martinez Del Pero M, Chaudhry A, Jones RB, Sivasothy P, Jani P, Jayne D. B-cell depletion with rituximab for refractory head and neck Wegener's granulomatosis: a cohort study. Clin Otolaryngol. 2009;34(4):328-35.

22. Hennekam RCM, Allanson JE, Krantz ID, Gorlin RJ. Gorlin's syndromes of the head and neck. 5th ed. New York: Oxford University Press; 2010.

23. Toupenay S, Razanamihaja N, Berdal A, Boy-Lefevre ML. Rare disesases with oral components: care course and quality of life. Community Dent Health. 2013;30:10-4

\section{Submit your next manuscript to BioMed Central and we will help you at every step:}

- We accept pre-submission inquiries

- Our selector tool helps you to find the most relevant journal

- We provide round the clock customer support

- Convenient online submission

- Thorough peer review

- Inclusion in PubMed and all major indexing services

- Maximum visibility for your research

Submit your manuscript at www.biomedcentral.com/submit
Biomed Central 